\title{
Comparative analysis of diosgenin in Dioscorea species and related medicinal plants by UPLC-DAD-MS
}

Tao $\mathrm{Yi}^{{ }^{*}{ }^{*}}$, Lan-Lan Fan ${ }^{2+}$, Hong-Li Chen ${ }^{3}$, Guo-Yuan Zhu ${ }^{4}$, Hau-Man Suen ${ }^{1}$, Yi-Na Tang ${ }^{1}$, Lin Zhu' ${ }^{1}$ Chu Chu ${ }^{5}$, Zhong-Zhen Zhao ${ }^{1}$ and Hu-Biao Chen ${ }^{1 *}$

\begin{abstract}
Background: Dioscorea is a genus of flowering plants, and some Dioscorea species are known and used as a source for the steroidal sapogenin diosgenin. To screen potential resource from Dioscorea species and related medicinal plants for diosgenin extraction, a rapid method to compare the contents of diosgenin in various plants is crucial.

Results: An ultra-performance liquid chromatography (UPLC) coupled with diode array detection (DAD) and electrospray ionization mass spectrometry (ESI-MS) method was developed for identification and determination of diosgenin in various plants. A comprehensive validation of the developed method was conducted. Twenty-four batches of plant samples from four Dioscorea species, one Smilax species and two Heterosmilax species were analyzed by using the developed method.

The present method presented good sensitivity, precision and accuracy. Diosgenin was found in three Dioscorea species and one Heterosmilax species, namely D. zingiberensis, D. septemloba, D. collettii and H. yunnanensis.
\end{abstract}

Conclusion: The method is suitable for the screening of diosgenin resources from plants. D. zingiberensis is an important resource for diosgenin harvesting.

Keywords: Diosgenin, UPLC-DAD-MS, Dioscorea, Medicinal plants, Quality evaluation

\section{Background}

Dioscorea (yam) is a genus of over 600 species of flowering plants in the family Dioscoreaceae, native throughout the tropical and warm temperate regions of the world. Apart from the traditional importance as starchy staple food (such as D. opposita, D. alata and D. japonica) [1], some Dioscorea species are known and used as a source for the steroidal sapogenin diosgenin, a precursor for the synthesis of steroid drugs [2]. However, the reserves of wild Dioscorea plants continue to decline, because of the extensive harvesting and increasingly ecological damage [3]. Yet the failure of achieving fully chemical synthesis of steroids until now again made Dioscorea a very attractive source for steroidal precursors.

\footnotetext{
* Correspondence: yitao@hkbu.edu.hk; hbchen@hkbu.edu.hk

${ }^{\dagger}$ Equal contributors

'School of Chinese Medicine, Hong Kong Baptist University, Hong Kong Special Administrative Region, PR China

Full list of author information is available at the end of the article
}

China and Mexico are the top two countries with the richest yam resource in the world, the yield of diosgenin accounts for $67 \%$ of world production [4]. As far as we know, there are 49 species of the genus Dioscorea distributed in China, and some related medicinal plants are confusedly used in the folk medicine [5-7]. In recent decades, diverse medicinal plants from the genera Dioscorea and Smilax, and even minor species from the genus Heterosmilax, have been documented under the name "Bixie" or a very similar name as folk medicines in different areas of China [8-10]. However, it has not been reported whether they can be used as a source for steroidal sapogenin diosgenin. This situation limits the comprehensive utilization of these plant resources. Therefore, to overcome the shortage of raw materials and to support sustainable development of the pharmaceutical industry associated with diosgenin, screening of potential plants resource from Dioscorea species and related medicinal plants for diosgenin extraction is 
urgently needed. Undoubtedly, to develop a rapid method which can compare the contents of diosgenin in various plants remains the primary task.

To solve this problem, some studies have attempted to analyze diosgenin in these medicinal plants by using colorimetry $[11,12]$, thin layer chromatography (TLC) $[13,14]$ and high performance liquid chromatography (HPLC) [15-17]. However, the specificity and precision of colorimetry and TLC were unsatisfactory. The current HPLC method also seems time-consuming. Moreover, the reported contents only partially contributed to diosgenin screening from the genus, because the analytical methods varied considerably. Ultra performance liquid chromatography (UPLC) is a relatively new technique giving new possibilities in saving of analysis time and solvent consumption. UPLC combined with photodiode array detection (PAD) and mass spectrometric (MS) techniques can provide online ultraviolet (UV) and MS information for each analyte in a chromatogram, and this has been proven to be a powerful tool for the rapid qualitative and quantitative analyses of the constituents in botanic extracts and herbal products [18-20].

In the present study, a UPLC-DAD-MS method was developed for the analysis of diosgenin in four Dioscorea species and related medicinal plants including one Smilax species and two Heterosmilax species. The results demonstrated that our method is highly precise and accurate, which is suitable for the screening of diosgenin resources from plants. Among the tested plant samples, diosgenin was found in three Dioscorea species and one Heterosmilax species, namely $D$. zingiberensis, $D$. septemloba, $D$. collettii and $H$. yunnanensis. Our reserch demonstrated that D. zingiberensis is an important resource for diosgenin harvesting.

\section{Methods \\ Materials}

The sources of the tested samples are listed in Table 1. Identity of the samples was confirmed by Dr. Hubiao Chen, School of Chinese Medicine, Hong Kong Baptist University [21,22]. Corresponding voucher specimens were deposited in the Chinese medicines center, Hong Kong Baptist University. (No. DYSY for D. zingiberensis, No. MBX for D. septemloba, No. CRSY for D. collettii, No. SY for D. opposita, No. GYBQ for Smilax glbra, No. XBQ for Heterosmilax japonica, No. DZXBQ for H. yunnanensis, respectively).

\section{Reagents and chemicals}

Acetonitrile of HPLC grade and methanol of analytical grade were purchased from Lab-scan (Bangkok, Thailand). Hydrochloric acid (c.a. 37\%) and chloroform purchased from Lab-scan (Bangkok, Thailand) were used for the acid hydrolysis and partition of samples. Water was purified
Table 1 Contents of diosgenin in Dioscorea species and related medicinal plants

\begin{tabular}{|c|c|c|}
\hline Species & Source and year of harvest & Diosgenin $(\mathrm{mg} / \mathrm{g})$ \\
\hline \multirow[t]{10}{*}{ D. zingiberensis } & $\begin{array}{l}\text { 1) Lingbao, Henan, } \\
\text { China (2011) }\end{array}$ & $11.47 \pm 0.43$ \\
\hline & $\begin{array}{l}\text { 2) Huaihua, Hunan, } \\
\text { China (2010) }\end{array}$ & $11.23 \pm 0.29$ \\
\hline & 3) Shanxi, China (2010) & $18.35 \pm 0.52$ \\
\hline & $\begin{array}{l}\text { 4) Yuanling, Hunan, } \\
\text { China (2012) }\end{array}$ & $19.52 \pm 0.51$ \\
\hline & 5) Hubei (2012) & $13.20 \pm 0.36$ \\
\hline & $\begin{array}{l}\text { 6) Anhua, Hunan, } \\
\text { China (2012) }\end{array}$ & $11.30 \pm 0.36$ \\
\hline & $\begin{array}{l}\text { 7) Chenxi, Hunan, } \\
\text { China (2012) }\end{array}$ & $16.58 \pm 0.57$ \\
\hline & $\begin{array}{l}\text { 8) Xupu, Hunan, } \\
\text { China (2012) }\end{array}$ & $14.36 \pm 0.34$ \\
\hline & $\begin{array}{l}\text { 9) Zhongfang, Hunan, } \\
\text { China (2012) }\end{array}$ & $19.00 \pm 0.29$ \\
\hline & 10) Shanxi,China (2012) & $8.67 \pm 0.28$ \\
\hline \multirow[t]{5}{*}{ D. septemloba } & 1) Hunan, China (2011) & $0.78 \pm 0.02$ \\
\hline & 2) Hunan, China (2011) & $1.12 \pm 0.02$ \\
\hline & 3) Hunan, China (2011) & $1.11 \pm 0.04$ \\
\hline & 4) Hunan, China (2011) & $1.18 \pm 0.02$ \\
\hline & 5) Chengdu, China (2012) & $1.14 \pm 0.03$ \\
\hline D. collettii & 1) Guizhou, China (2012) & $13.19 \pm 0.26$ \\
\hline \multirow[t]{3}{*}{ D. opposita } & 1) Henan, China (2011) & ND \\
\hline & 2) Henan, China (2011) & ND \\
\hline & $\begin{array}{l}\text { 3) Jiaozuo, Henan, } \\
\text { China (2011) }\end{array}$ & ND \\
\hline \multirow[t]{3}{*}{ Smilax glabra } & $\begin{array}{l}\text { 1) Shek Lei Pui Reservoir, } \\
\text { Hong Kong (2012) }\end{array}$ & ND \\
\hline & 2) Duyun, Guizhou (2011) & ND \\
\hline & $\begin{array}{l}\text { 3) Kam Shan Country Park, } \\
\text { Hong Kong (2012) }\end{array}$ & ND \\
\hline Heterosmilax japonica & $\begin{array}{l}\text { 1) Ceheng, Guizhou, } \\
\text { China (2010) }\end{array}$ & ND \\
\hline H. yunnanensis & $\begin{array}{l}\text { 1) Ceheng, Guizhou, } \\
\text { China (2010) }\end{array}$ & $0.05 \pm 0.002$ \\
\hline
\end{tabular}

All values are expressed as mean \pm standard deviation $(n=3)$. $\mathrm{ND}=$ Not detected.

using a Milli-Q water system (Millipore; Bedford, MA, USA).

The standard compound of diosgenin was purchased from Phytomarker Ltd. (Tianjin, China). The purity of diosgenin was determined to be more than $98 \%$ by normalization of the peak area detected by UPLC-DAD. The chemical structure of diosgenin is shown in Figure 1.

\section{UPLC-DAD-MS instrumentation and conditions}

A Waters Acquity ${ }^{\text {Tw }}$ ultra performance liquid chromatography (UPLC) system (Waters Corp., Milford, USA) 


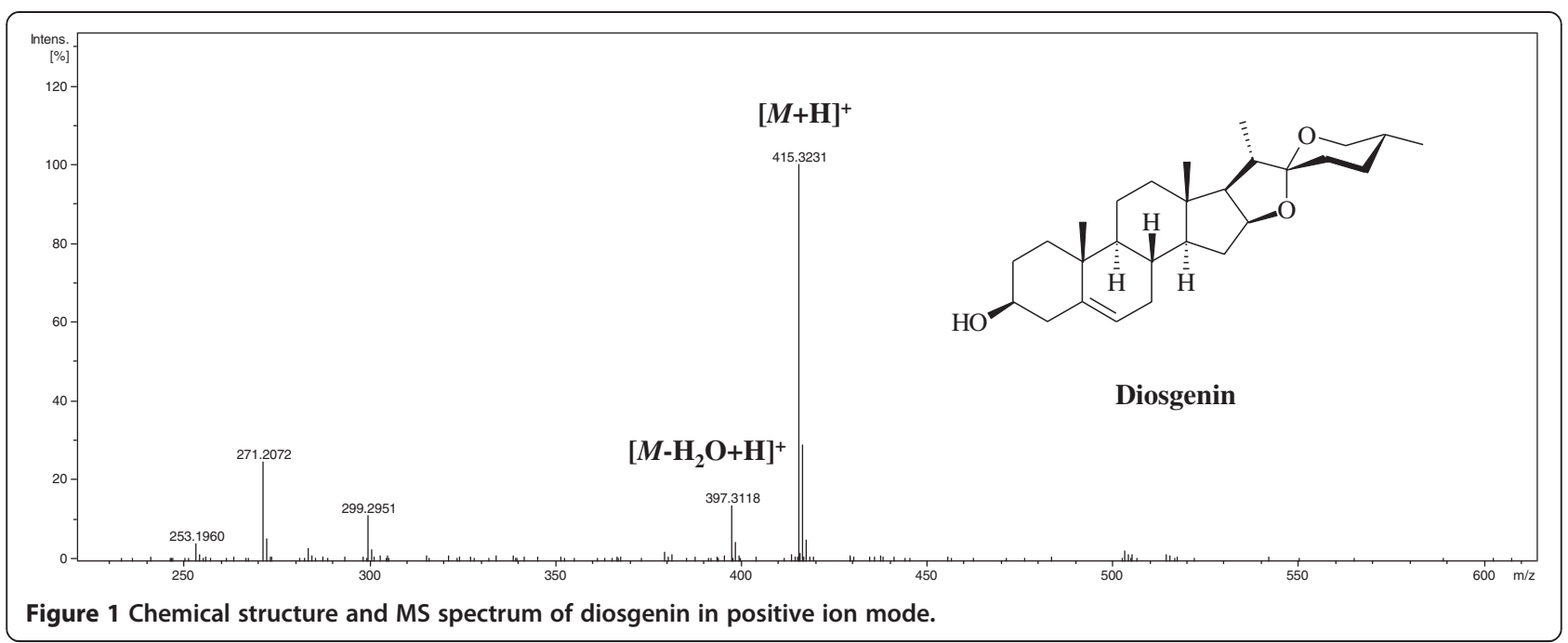

with photodiode array detection (PAD), was hyphenated to a Bruker MicrOTOFQ system by an electrospray ionization (ESI) interface (Bruker Daltonics, Bremen, Germany) for chromatographic and mass spectrometric (MS) analysis. Data analysis was conducted using DataAnalysis software version 4.0 (Bruker Daltonics). For chromatographic separation, a Waters $\mathrm{BEH} \mathrm{C}_{18}$ column $(1.7 \mu \mathrm{m}, 2.1 \times 100 \mathrm{~mm})$ with a VanGuard ${ }^{\mathrm{m}}$ pre-column (BEH, $\mathrm{C}_{18}, 1.7 \mu \mathrm{m}, 2.1 \times 5 \mathrm{~mm}$ ) was used. The mobile phase consisted of $0.1 \%$ formic acid in water (A) and $0.1 \%$ formic acid in acetonitrile (B) using an isocratic elution of $82 \%$ (B) in $0-10 \mathrm{~min}$. The solvent flow rate was $0.3 \mathrm{~mL} / \mathrm{min}$, the column temperature was set to $40^{\circ} \mathrm{C}$, and the detection wavelength was $203 \mathrm{~nm}$. The conditions of MS analysis in the positive ion mode were as follows: drying gas (nitrogen), flow rate, $8 \mathrm{~L} / \mathrm{min}$; gas temperature, $180^{\circ} \mathrm{C}$; scan range, $50-1600 \mathrm{~m} / \mathrm{z}$; end plate offset voltage, $-500 \mathrm{~V}$; capillary voltage, $4500 \mathrm{~V}$; nebulizer pressure, 2.5 Bar.

\section{Preparation of standard and sample solutions}

The stock solution of diosgenin $(1000 \mathrm{mg} / \mathrm{L})$ were prepared in methanol and stored in the refrigerator. The working solutions were prepared by appropriate dilution

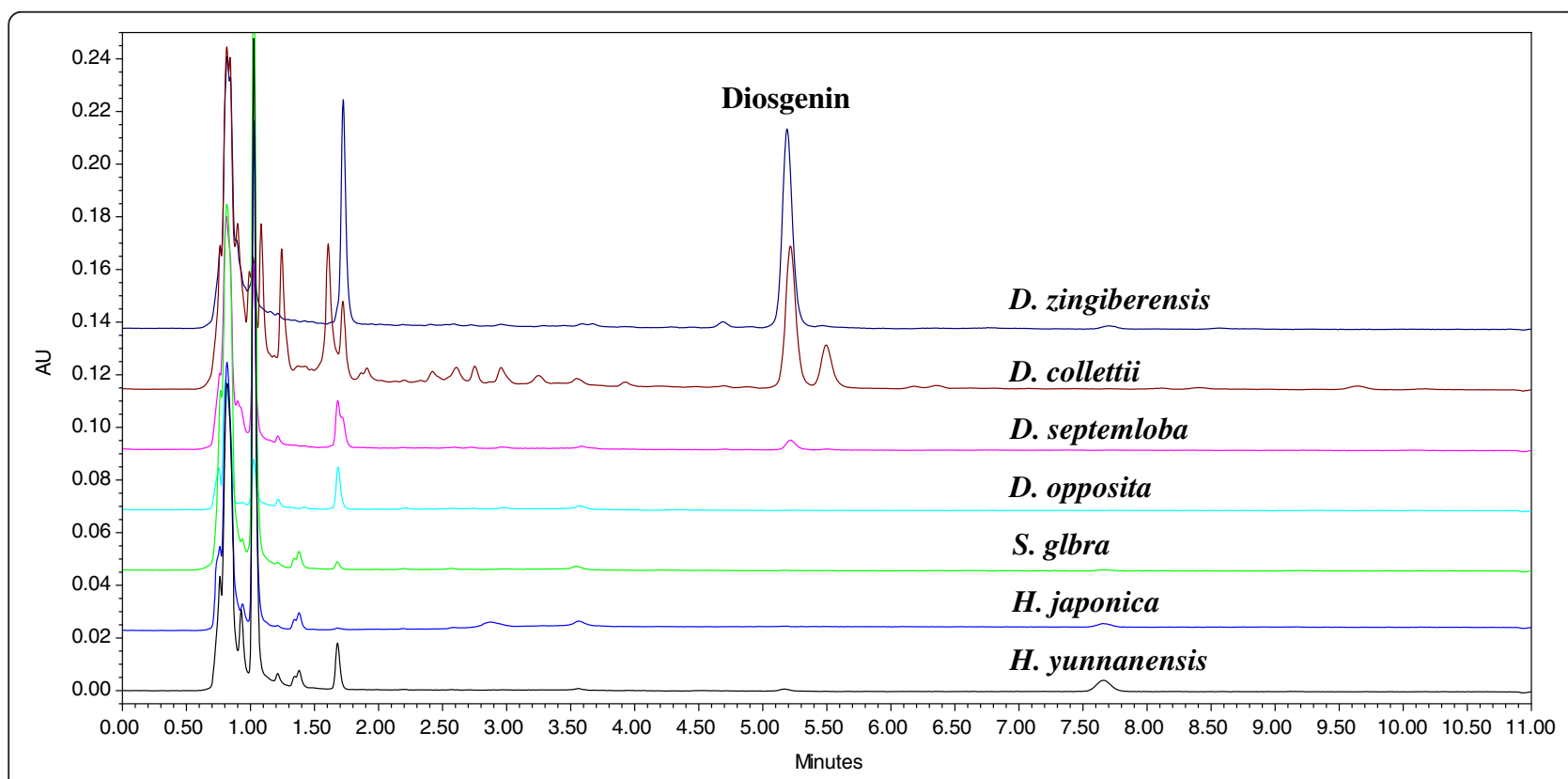

Figure 2 Typical UPLC chromatograms of plant samples using DAD at $203 \mathrm{~nm}$. 
Table 2 Mass spectral characteristics of diosgenin

\begin{tabular}{lllllll}
\hline Retention time $(\mathbf{m i n})$ & Analyte & Formula & Selected ion & $\mathbf{m} / \mathbf{z}$ calculated & $\mathbf{m} / \mathbf{z}$ observed & Error $(\mathbf{p p m})$ \\
\hline 5.2 & Diosgenin & $\mathrm{C}_{27} \mathrm{H}_{43} \mathrm{O}_{3}$ & {$[\mathrm{M}+\mathrm{H}]^{+}$} & 415.3212 & 415.3231 & 1.9 \\
& & $\mathrm{C}_{27} \mathrm{H}_{41} \mathrm{O}_{2}$ & {$\left[\mathrm{M}-\mathrm{H}_{2} \mathrm{O}+\mathrm{H}\right]^{+}$} & 397.3107 & 397.3118 & 1.1 \\
\hline
\end{tabular}

of the stock solutions with methanol, and the resulting concentrations were $1,5,10,50,100,200$, and $500 \mathrm{mg} / \mathrm{L}$, respectively. An aliquot of $5 \mu \mathrm{L}$ for each calibration standard solution was injected for UPLC analysis.

The preparation of sample solution was prescribed in our study [23]. Briefly, plant materials were cut into small pieces and mixed thoroughly. A representative portion of the sample pieces was ground into a powder that passed through a 20 mesh $(0.9 \mathrm{~mm})$ sieve. Herbal sample powder $(0.5 \mathrm{~g})$ was extracted with $15 \mathrm{~mL}$ of methanol by means of sonication at room temperature for $0.5 \mathrm{~h}$. The operations were repeated two times, and the residue was washed with $5 \mathrm{~mL}$ of fresh extraction solvent. Total extracts were combined in a 50-mL volumetric flask, which was filled up to the calibration mark with extraction solvent. The sample solution of $25 \mathrm{~mL}$ for glycoside assay was transferred into a round-bottomed flask and evaporated to dryness by rotary evaporation under vacuum at $60^{\circ} \mathrm{C}$. An amount of $20 \mathrm{~mL}$ hydrochloric acid solution (10\%) was added to the residue, heated to hydrolyse on a water bath for $30 \mathrm{~min}$, cooled, and washed with $10 \mathrm{~mL}$ of chloroform each time for three times. After the combined mixture was extracted and partitioned, the lower layer (chloroform layer) was collected and the upper layer was extracted with an additional $30 \mathrm{~mL}$ of chloroform once. The combined chloroform layer was evaporated to dryness and the residue was dissolved by an appropriate amount of methanol, transferred to a $25 \mathrm{~mL}$ volumetric flask and the volume was made up to the calibration mark with methanol. The extracts were then filtered through a syringe filter $(0.2 \mu \mathrm{m})$. An aliquot of $5 \mu \mathrm{L}$ solution was injected for UPLC-MS analysis.

\section{Assay validation and sample determination}

Calibration curve is established for each standard compound. D. zingiberensis of batch 1 from Lingbao was chosen for method validation. Repeatability was evaluated in intra- and inter-day assays. Recovery of all the quantified constituents was determined by sample in different concentration levels using a mixture of standards with 50, 100 and 200\% of the quantified levels of constituents in the samples. All plant samples collected from various regions were analyzed using the present method.

\section{Results and discussion}

Optimization of extraction and hydrolysis conditions

Various extraction methods (e.g. reflux, sonication), solvents (e.g. different concentrations of methanol or ethanol) and times of extraction were evaluated to obtain maximum extraction efficiency. The results demonstrated that there was no significant difference in the yield of analytes between sonication and reflux, and exhaustive extraction was achieved by sonication with methanol three times for $30 \mathrm{~min}$ each time. Hydrolysis conditions were optimized according to the method mentioned in the Chinese Pharmacopeia (2005 edition). Hydrochloric acid rather than sulfuric acid was used because of its low boiling point and good volatility. Chloroform was used as the extraction solvent after hydrolysis because of incompatibility with water and good solubility with diosgenin. The other parameters, including solvent volume, acid concentration, hydrolysis time and extraction times, were further tested. The final conditions are presented in detail in the section of "Preparation of standard and sample solutions".

\section{Chromatographic conditions and online ESI/MS identification}

The chromatographic conditions such as column, mobile phase and gradient elution were optimized in the preliminary test to achieve better symmetry and shorter retention time of chromatographic peak. After comparing Waters HSS $\mathrm{C}_{18}$ column and $\mathrm{BEH} \mathrm{C}_{18}$ column, $\mathrm{BEH} \mathrm{C}_{18}$ column was selected as analytical column, because a symmetrical peak of diosgenin was obtained. Mobile phase, such as acetonitrile-water and methanol-water, was compared on a HSS $\mathrm{C}_{18}$ column and $\mathrm{BEH} \mathrm{C}_{18}$ column at different temperatures. The results showed that satisfactory separation could best be obtained by eluting plant samples on a $\mathrm{BEH} \mathrm{C}_{18}$ column at $40^{\circ} \mathrm{C}$ using an isocratic flow of acetonitrile and water within $10 \mathrm{~min}$. After comparing the UV chromatograms recorded at wavelengths from 190 to $500 \mathrm{~nm}, 203 \mathrm{~nm}$ was chosen as the wavelength to determine diosgenin in various plants (Figure 2).

The mass spectrometric conditions were optimized in both positive and negative ion modes; the positive ion mode was found to be more sensitive. In order to

Table 3 Linearity factors, LOD and LOQ of diosgenin

\begin{tabular}{llllll}
\hline Analyte & Equation & Range $(\mathbf{m g} / \mathbf{L})$ & $\boldsymbol{R}^{\mathbf{2}}$ & LOD (ng) \\
\hline Diosgenin & $y=2259.94 \times+158.19$ & $1-500$ & 0.9998 & 0.3 \\
\hline
\end{tabular}


Table 4 Precision, repeatability and stability of the method

\begin{tabular}{|c|c|c|c|c|c|c|c|c|c|}
\hline \multirow[t]{3}{*}{ Analyte } & \multirow{3}{*}{$\begin{array}{l}\text { Precision } \\
\text { RSD }(\%, n=6)\end{array}$} & \multicolumn{7}{|l|}{ Repeatability } & \multirow{3}{*}{$\begin{array}{l}\text { Stability } \\
\text { RSD }(\%, n=6)\end{array}$} \\
\hline & & \multicolumn{2}{|l|}{ Day 1} & \multicolumn{2}{|l|}{ Day 2} & \multicolumn{2}{|l|}{ Day 3} & \multirow{2}{*}{$\begin{array}{l}\text { Inter-day } \\
\text { RSD (\%) }\end{array}$} & \\
\hline & & $\begin{array}{l}\text { Determined } \\
\text { ( } \mathrm{mg} / \mathrm{g})\end{array}$ & RSD (\%) & $\begin{array}{l}\text { Determined } \\
\text { ( } \mathrm{mg} / \mathrm{g})\end{array}$ & RSD (\%) & $\begin{array}{l}\text { Determined } \\
\text { (mg/g) }\end{array}$ & RSD (\%) & & \\
\hline Diosgenin & 2.40 & $11.01 \pm 0.24$ & 2.18 & $11.47 \pm 0.43$ & 3.73 & $11.10 \pm 0.22$ & 2.01 & 2.16 & 4.57 \\
\hline
\end{tabular}

promote the formation of quasi-molecular ions $[M+\mathrm{H}]^{+}$ in MS analysis, $0.1 \%$ formic acid was used in the mobile phase. MS offset voltage was further adjusted to generate characteristic fragments of diosgenin. A typical MS chromatogram and MS characteristics obtained from the analysis of a plant sample is shown in Figure 1 and Table 2.

\section{Validation of the analysis method}

The linearity, regression and linear ranges of diosgenin were summarized in Tables 3, 4 and 5. The data indicated good linearity between concentrations and peak areas of the analytes within the test ranges $\left(R^{2} \geq 0.999\right)$. Based on visual evaluation with a signal-to-noise ratio of about 3:1 and 10:1, the LOD and LOQ of diosgenin were found to be 0.3 and $0.8 \mathrm{ng}$, respectively. Therefore, the system was considered to be sensitive for the analysis. The RSD of intra and inter day diosgenin variations did not exceed $3.73 \%$ and $2.16 \%$, respectively. The established method also had acceptable accuracy with average recovery of $99.43 \%$ for diosgenin. As to stability test, the RSDs of the peak areas for diosgenin detected within $24 \mathrm{~h}$ were lower than $4.57 \%$. All these results demonstrated that the developed UPLC method was sufficiently reliable and accurate and is therefore suitable for quantification of diosgenin in herbal extract.

\section{Sample analysis}

The present method was successfully applied to the quantification of diosgenin in herbal samples from different localities. The results are summarized in Table 1. The results demonstrated a variation in the contents of the quantified constituents in testes samples. Such variations may presumably be attributed to differences in plant resources.

The data demonstrated that D. opposita, Smilax glbra, Heterosmilax japonica do not contain diosgenin. In China, $D$. opposite is mainly consumed as starchy staple food $[24,25]$, while $S$. glbra and $H$. japonica are mainly used as folk medicine [26-28]. D. collettii, D. septemloba and H. yunnanensis contain diosgenin, but the number of the tested samples is still relatively small. Further investigation based on a large number of samples is needed. It's worth noting that the content of diosgenin is up to $19.52 \mathrm{mg} / \mathrm{g}$ in D. zingiberensis, and the average content of diosgenin in ten batches is $14.37 \mathrm{mg} / \mathrm{g}$. The abundance of diosgenin in D. zingiberensis is higher than those in D. nipponica (12.52 $\mathrm{mg} / \mathrm{g}$ ) and D. panthaica (5.29 $\mathrm{mg} / \mathrm{g}$ ) [23], the other two Dioscorea species used for diosgenin extraction in China. Moreover, D. zingiberensis is widely distributed in China, including Hennan, Hubei, Hunan, Shanxi, Gansu and Sichaun provinces. Therefore, D. zingiberensis is an important plant resource for diosgenin acquisition.

\section{Conclusions}

A UPLC-DAD-MS method was developed for comparative analysis of diosgenin in Dioscorea species and related medicinal plants. With respect to already existing reports, the present method, hyphenating UPLC to both DAD and MS techniques, has the advantages of faster, more accurate, and comparative analysis of various herbal samples. By comparing the diosgenin contents, the results demonstrated that D. zingiberensis is one of important plant resources for diosgenin harvesting. Our study significantly contributes to the research and development of medicinal plants, especially for the screening of resource plants for diosgenin.

\section{Abbreviations}

UPLC: Ultra performance liquid chromatography; DAD: Diode array detection; ESI: Electrospray ionization; MS: Mass spectrum; TLC: Thin layer chromatography; HPLC: High performance liquid chromatography.

\section{Competing interests}

The authors declare that they have no competing interests.

\section{Authors' contributions}

TY and LLF initiated and all authors designed the study. The sample extraction was conducted by YNT and HMS. The optimization of experimental conditions was performed by LZ and CC. The data analysis was conduct by HLC and GYZ. ZZZ and HBC drafted the manuscript. All authors contributed to data analysis and manuscript finalization. All authors read and approved the final manuscript.

Table 5 Recovery of diosgenin in method accuracy test

\begin{tabular}{|c|c|c|c|c|c|c|c|c|}
\hline \multirow[t]{2}{*}{ Analyte } & \multicolumn{2}{|l|}{$50 \%$} & \multicolumn{2}{|l|}{$100 \%$} & \multicolumn{2}{|l|}{$200 \%$} & \multicolumn{2}{|l|}{ Average } \\
\hline & Recovery (\%) & RSD (\%) & Recovery (\%) & RSD (\%) & Recovery (\%) & RSD (\%) & Recovery (\%) & RSD (\%) \\
\hline Diosgenin & $102.47 \pm 2.54$ & 2.48 & $100.51 \pm 2.53$ & 2.51 & $95.30 \pm 3.22$ & 3.38 & 99.43 & 3.73 \\
\hline
\end{tabular}

Values shown are mean \pm standard deviation $(n=3)$. 


\section{Acknowledgements}

This research was funded by the Faculty Research Grant of Hong Kong Baptist University (FRG2/13-14/031 and FRG1/12-13/035), the Health Department of Guangxi province (Zhong2010111 and Z2010175) and Guangxi Administration of Traditional Chinese Medicine (GZKZ1131) of China.

\section{Author details}

${ }^{1}$ School of Chinese Medicine, Hong Kong Baptist University, Hong Kong Special Administrative Region, PR China. ${ }^{2}$ Guangxi Botanical Garden of Medicinal Plant, Nanning, Guangxi 530023, China. ${ }^{3}$ Department of Chemistry, Lanzhou University, Lanzhou 730000, China. ${ }^{4}$ The State Key Laboratory of Quality Research in Chinese Medicine, Macau University of Science and Technology, Macau, China. ${ }^{5}$ College of Pharmaceutical Science, Zhejiang University of Technology, Hangzhou 310014, China.

Received: 18 April 2014 Accepted: 31 July 2014

Published: 9 August 2014

\section{References}

1. Adedayo CB, Oboh G, Ademiluyi AO, Akindaahunsi AA: Comparative studies on antioxidant properties of some tropical Nigerian yam varieties (Dioscorea spp.). Adv Food Sci 2011, 33:28-33.

2. Balandrin MF, Klocke JA, Wurtele ES, Bollinger WH: Natural plant chemicals: sources of industrial and medicinal materials. Science 1985, 228:1154-1160.

3. Coursey DG: Yams. An Account of the Nature, Origins, Cultivation and Utilisation of the Useful Members of the Dioscoreaceae. London: Longmans; 1967.

4. Li X, Ma JZ, Shi YD: Research progress and prospects of Dioscorea and diosgenin. Chem Ind Forest Prod 2010, 30:107-112.

5. Editorial Board of Flora of China, Chinese Academy of Sciences: Flora of China, Vol. 16. Beijing: Science Press; 1985:54-55. 60, 68.

6. Li XZ, Jin GZ: The study progress of Bixie. Chinese Wild Plant Resour 2002, 21:8-10.

7. Sautour M, Mitaine-Offer AC, Lacaille-Dubois MA: The Dioscorea genus: a review of bioactive steroid saponins. J Nat Med 2007, 61:91-101.

8. Zhao WL: The observation on leaf surface of original plants of four crude "BI-XIE" by SEM. Chin J Mod Appl Pharm 1999, 16:16-18.

9. Editorial Committee of Chinese Materia Medica: State Administration of Chinese Traditional Medicine of P.R. China, Vol. 8. Shanghai: Science and Technology Press; 1998:230-234.

10. Xu GJ, Xu LS: Species Systematization and Quality Evaluation of Commonly Used Chinese Traditional Drugs. South-China Edition, Vol. 2. Fuzhou: Fujian Science \& Technology Publishing House; 1997:431-435. 504-506.

11. Panina W, Loshkarev PM: Colorimetric method of determining diosgenin in Dioscorea. Med Prom SSSR 1963, 17:45-48.

12. Wang GZ, Liu WW, Ge RB, Zhang M, Liu YW: Determination of total saponins in Dioscorea zingiberensis C.H. Wright by colorimetric analysis. $J$ Hubei University Chinese Med 2008, 10:44-45.

13. Wang L, Wang X, Yuan X, Zhao B: Simultaneous analysis of diosgenin and sarsasapogenin in Asparagus officinalis byproduct by thin-layer chromatography. Phytochem Anal 2011, 22:14-17.

14. Amir M, Ahmad A, Siddique NA, Mujeeb M, Ahmad S, Siddique WA: Development and validation of HPTLC method for the estimation of diosgenin in In Vitroculture and rhizome of Dioscorea deltoidea. Acta Chromatogr 2012, 24:111-121.

15. Yang $H$, Chen B, Wang XB, Chue PW, Shen YP, Xia GH, Jia XB: Rapid quantitative analysis of diosgenin in the tubers of Dioscorea zingiberensis C.H. Wright by couplingcellulose enzymolysis and two-phase acid hydrolysis in tandem with HPLC-UV. Nat Prod Res 2013, 27:1933-1935.

16. Gu YM, Yuan LH, Li WQ, Ouyang PK: Determination of diosgenin in Dioscoreo zingiberensis cell by RP-HPLC. Nat Prod Res Dev 2004, 16:331-333.

17. Shen Z, Zhang WT, Zhao WL: Simultaneous determination of four major steroidal saponins in seven species of Dioscorea L. by HPLC-ELSD. Chin Herb Med 2011, 3:70-74.

18. Yi T, Chen HB, Zhao ZZ, Jiang ZH, Cai SQ, Wang TM: Comparative analysis of the major constituents in the traditional Tibetan medicinal plants Saussurea laniceps and S. medusa by LC-DAD-MS. Chromatographia 2009, 70:957-962.

19. Yi T, Zhang JY, Zhao ZZ, Yang ZJ, Chen HB: Characterization and determination of six flavonoids in the ethnomedicine "Dragon's Blood" by UPLC-PAD-MS. Chem Cent J 2012, 6:116.
20. Yi T, Chen QL, He XC, So SW, Lo YL, Fan LL, Xu J, Tang YN, Zhang JY, Zhao ZZ, Chen HB: Chemical quantification and antioxidant assay of four active components in Ficus hirta root using UPLC-PAD-MS fingerprinting combined with cluster analysis. Chem Cent J 2013, 7:115.

21. Tang YN, Zhang H, Li J, Yi T: Pharmacognostic identification of original plants of rhizoma Dioscoreae nipponica and rhizoma Dioscoreae panthaicae. West China J Pharm Sci 2008, 23:444-447.

22. Tang YN, He XC, Chen QL, Fan LL, Zhang JY, Zhao ZZ, Dong LS, Liang ZT, Yi $T$, Chen HB: A mixed microscopic method for differentiating seven species of "Bixie"-related Chinese Materia Medica. Microsc Res Tech 2014, 77:57-70.

23. Tang Y, Yi T, Chen H, Zhao Z, Liang Z, Chen H: Quantitative comparison of multiple components in Dioscorea nipponica and $D$. panthaica by ultrahigh performance liquid chromatography coupled with quadrupole time-of-flight mass spectrometry. Phytochem Anal 2013, 24:413-422.

24. Nagai T, Nagashima T: Functional properties of dioscorin, a soluble viscous protein from Japanese yam (Dioscorea opposita thunb.) tuber mucilage Tororo. Z Naturforsch C 2006, 61:792-798.

25. Nagai T, Suzuki N, Nagashima T: Antioxidative activity of water extracts from the yam (Dioscorea opposite Thunb.) tuber mucilage tororo. Eur J Lipid Sci Technol 2006, 108:526-531.

26. Iddamaldeniya SS, Wickramasinghe N, Thabrew I, Ratnatunge N, Thammitiyagodage MG: Protection against diethylnitrosoamine-induced hepatocarcinogenesis by an indigenous medicine comprised of Nigella sativa, Hemidesmus indicus and Smilax glabra: a preliminary study. J Carcinog 2003, 2:6.

27. Thabrew MI, Mitry RR, Morsy MA, Hughes RD: Cytotoxic effects of a decoction of Nigella sativa, Hemidesmus indicus and Smilax glabra on human hepatomaHepG 2 cells. Life Sci 2005, 77:1319-1330.

28. Kuai $Y H$, Hai $L N$, Jian $X Y$, Zhang SJ: Progress in medicinal plant of Heterosmilax. China J Exp Traditional Med Formulae 2010, 16:207-209.

\section{doi:10.1186/1471-2091-15-19}

Cite this article as: Yi et al: Comparative analysis of diosgenin in Dioscorea species and related medicinal plants by UPLC-DAD-MS. BMC Biochemistry 2014 15:19.

\section{Submit your next manuscript to BioMed Central and take full advantage of:}

- Convenient online submission

- Thorough peer review

- No space constraints or color figure charges

- Immediate publication on acceptance

- Inclusion in PubMed, CAS, Scopus and Google Scholar

- Research which is freely available for redistribution

Submit your manuscript at www.biomedcentral.com/submit
C Biomed Central 